\title{
STUDI KINETIKA EKSTRAK DAUN JAMBU BIJI SEBAGAI OBAT PENYEMBUH DIARE
}

\author{
MASNI RAHMAYANTI GAJA8 ${ }^{* 1}$ \\ ${ }^{1}$ Pendidikan Kimia,FMIPA, Universitas Negeri Padang, Indonesia \\ *E-mail : masnirahmayanti.2000@gmail.com
}

\begin{abstract}
ABSTRAK. Studi ini bertujuan untik membuat tumbukan daun jambu biji untuk menghilangkan rasa sakit perut atau bisa juga disebut dengan diare. Metode ini dilakukan adalah eksperimen dan uji aktivitas katalitik secara langsung. Tahap pertama di lakukan dengan tumbukan dari daun jambu biji. Uji aktivitas langsung dengan variasi 7 helai 2 sampai 3 kali perhari selama 2 hari. Hasil eksperimen membuktikan bahwa tumbukan daun jambu biji dapat menghilangkan rasa sakit perut atau diare. Kondisi optimum tercapai pada hari ke dua. Penyembuhan ini diduga karena aktivitas katalitik ekstrak mengandung flavonoid dan tanin dalam penyembuhan terhadap usus manusia.
\end{abstract}

Kata kunci : sakit perut, diare, katalitik, aktivitas, daun jambu biji, flavonoid, tanin, usus manusia.

\section{PENDAHULUAN}

Reaksi kimia ${ }^{(1-5)}$ adalah suatu proses dalam kehidupan sehari-hari yang selalu menghasilkan perubahan. Reaksi kimia ${ }^{(6-10)}$ dapat terjadi secara cepat dan lambat. Dimana reaksi kimia ${ }^{(11-15)}$ ada dikehidupan kita. Reaksi ${ }^{(16-20)}$ 
sangat penting untuk kita. Reaksi ${ }^{(21-25)}$ kimia $^{(26-30)}$ terdapat ditubuh kita, terdapat pada hewan maupun tumbuhan ${ }^{(31-35)}$. Reaksi kimia ${ }^{(36-40)}$ yang kita bahas adalah reaksi yang terjadi didalam perut. Dimana yang kita bahas adalah cara mengobati sakit perut atau diare dengan tumbukan daun jambu biji.

Katalis $^{(41-45)}$ adalah suatu cara untuk mempercepat suatu reaksi ${ }^{(46-50)}$. Didalam reaksi kimia sangat di perlukan katalis sebagai pembantu mempercepat reaksi. Yang ingin kita bahas adalah daunjambu biji sebagai katalis. Daun jambu biji digunakan sebagai katalis ${ }^{(51-55)}$ untuk mempercepat penyembuhan sakit perut atau diare. Ada beberapa diantara kita yang tidak tahu bahwa daun jambu biji dapat menyembuhkan penyakit yang kita alami. Tidak hanya sakit perut yang dapat di obati oleh daun jambu biji. Daun jambu biji juga dapat mengobati sakit yang ada pada kulit kita.

Nah, sakit perut adalah suatu hal yang tidak menyenangkan bagi kita. Sakit perut biasanya diakibatkan oleh beberapa faktor. Yang pertama makanan, yang kedua udara. Mengonsumsi makanan memang menyenangkan, namun kita tidak mengetahui apakah makanan itu baik untuk tubuh kita atau tidak. Dan udara dingin juga adalaah pemicu sakit perut dan diare ${ }^{(56-60)}$, hal ini menyebabkan kita lemas. Seperti biasanya, kemungkinan beberapa orang langsung membawa ke rumah sakit. Namun disini kita akan membahas sakit perut dapat diobati dengan cara alami atau sering juga disebut herbal.

Daun jambu biji adalah obat alami atau herbal ${ }^{(61-65)}$ yang dapat mengobati diare atau sakit perut. Daun jambu biji adalah tumbuhan yang sangat mudah kita temukan dimana pun kita berada. Dimana biji jambu biji ini mengandung flavonoid ${ }^{(66-70)}$, guercetin glycoside dan $\operatorname{tanin}^{(71-80)}$. Yang dikandung oleh daun jambu biji itulah yang dapat mengobati rasa sakit yang kita rasakan. Tanin, tanin adalah salah satu yang di miliki oleh daun 
jambu $^{(81-85)}$. Tanin ${ }^{(86-90)}$ berfungsi untuk mengecilkan pori-pori pada usus . karena adanya taninlah yang dapat membantu menyembuhkan rasa sakit yang kita rasakan.

Akibat pori-pori usus terbukalah sakit perut terjadi. Sakit perut kita ini juga dapat membuat kita lemas karena kehilangan banyak cairan. Nah, disuatu kota di Sumatera Utara tepatnya disidikalang. Disana ada salah satu penduduk yang memakan tumbukan daun jambu biji selama dua hari. Dan setelah dua hari rasa sakit perut yang beliau alami mereda dan bahkan tidak terasa sakit lagi. Jadi, sudah terbukti bahwa daun jambu biji dapat membantu kita dalam penyembuhan sakit perut atau diare.

\section{METODE}

\section{ALAT DAN BAHAN}

A. Alat :

1. Sendok ( Stainless steel )

2. Pisau ( Roch Messer )

3. Gelas ( Luminarc Conical)

B. Bahan

1. Daun jambu biji ( Sidikalang, Sumatera Utara) 


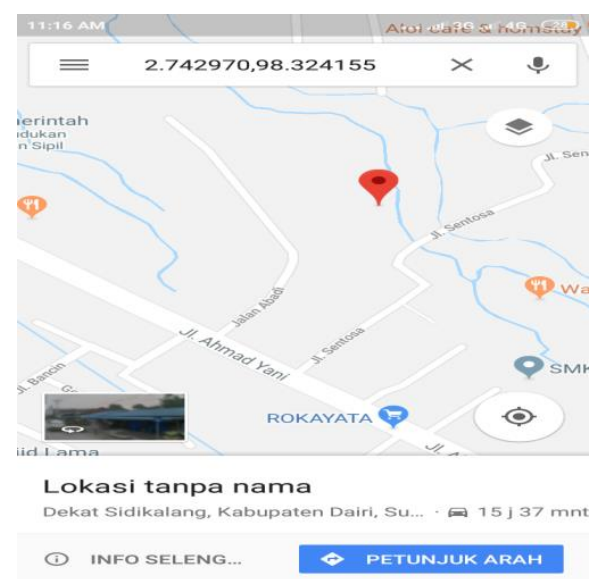

2. Air ( AQUA)

\section{PROSEDUR KERJA}

\section{Penyiapan sampel}

Penyiapan sampel diambil dari lokasi. Pada saat pengambilan diambil 7 helai daun jambu biji. Pembuatan ekstraknya ${ }^{(91-95)}$ dibuat dengan cara di tumbuk/haluskan daun biji jambu sebanyak 7 helai lalu masukkan aqua hingga halus lalu di saring. Setelah di campurkan tumbukan daun jambu biji ${ }^{(96-100)}$ tersebut dapat diminum atau di konsumsi. Dalam pengujian ekstrak $^{(101-105)}$ hasil yang saya dapat langsung dari orang yang bersangkutan. Jadi hal ini adalah obat yang sudah lazim untuk digunakan atau di konsumsi disaat sakit perut atau diare. 


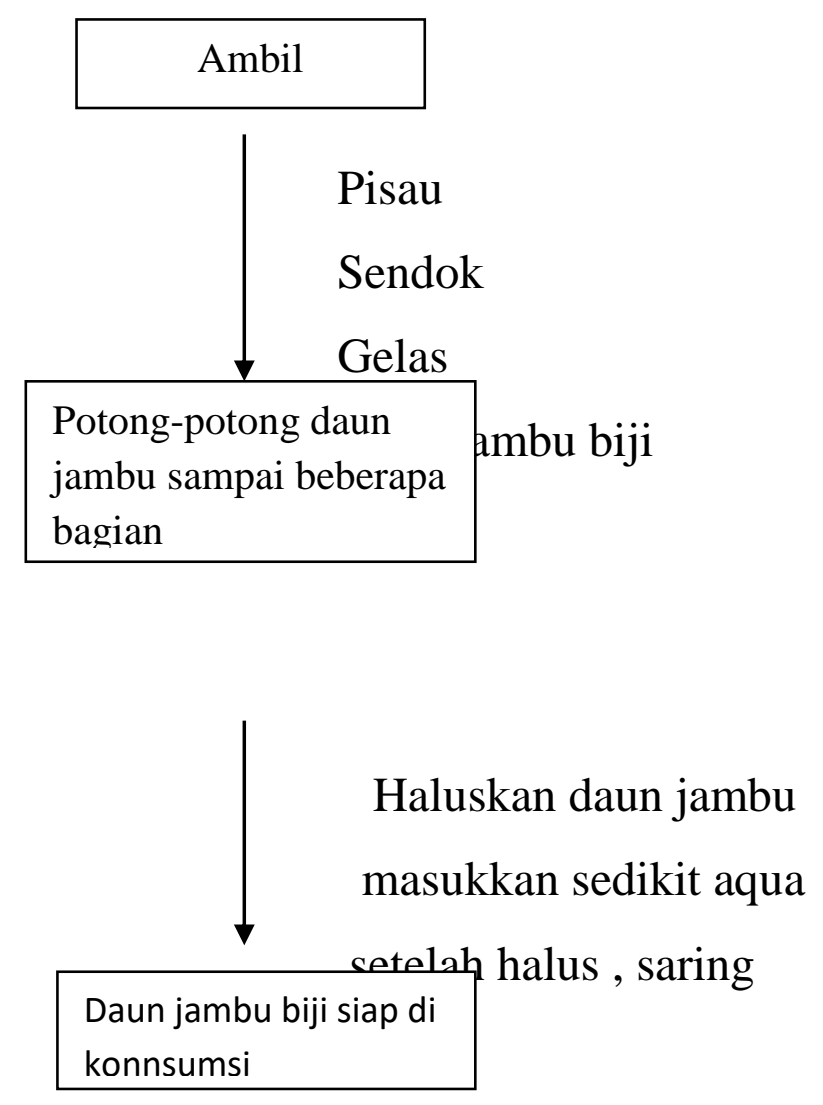




\section{PEMBAHASAN HASIL}

\section{Hasil Pembuatan}

Hasil dari pembuatan ekstrak diperoleh dari hasil penyaringan. Dapat kita lihat pada gambar berikut ini :

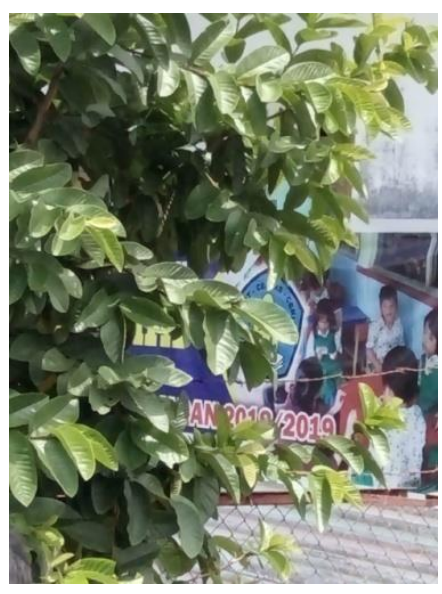

Pohon jambu biji

yang belum di petik

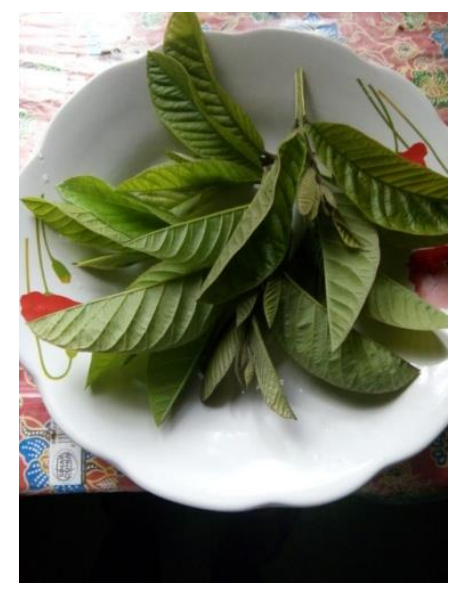

Daun jambu biji yang telah di petik

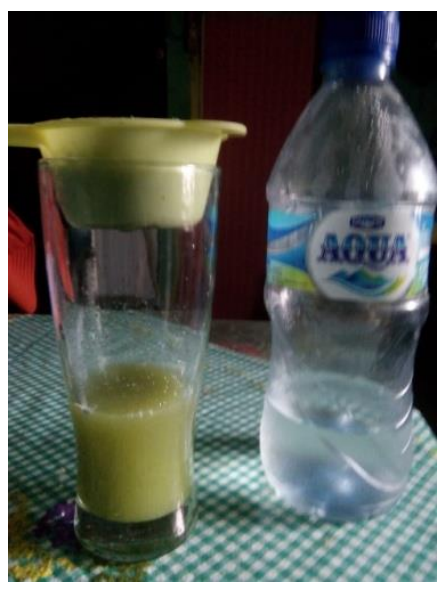

daun jambu biji telah di saring

Dari hasil uji coba ini, kita lakukan pada salah satu ibu yang tinggal di kabupaten Sidikalang di provinsi Sumatera Utara. Beliau memberikan kebenaran bahwa daun jambu biji sangat berkhasiat dan dapat mengobati sakit perut yang beliau alamai. Sebagaimana pada tabel berikut :

\section{Hasil Uji Coba}




\begin{tabular}{|l|l|}
\hline Pemakaian & Tingkat kesakitan \\
\hline $\begin{array}{l}\text { Peminuman } \\
\text { satu kali daun } \\
\text { jambu biji }\end{array}$ & $\bullet \bullet \bullet \bullet \bullet$ \\
\hline $\begin{array}{l}\text { Peminuman ke } \\
\text { dua kali daun } \\
\text { jambu biji }\end{array}$ & $\bullet \bullet \bullet \bullet$ \\
\hline $\begin{array}{l}\text { Peminuman ke } \\
\text { tiga kali daun } \\
\text { jambu biji }\end{array}$ & $\bullet \bullet \bullet$ \\
\hline $\begin{array}{l}\text { Peminuman Ke } \\
\text { empat kali }\end{array}$ & $\bullet \bullet$ \\
daun jambu \\
biji
\end{tabular}

Keterangan :

- adalah tingkat kesakitan yang

diderita.

\section{PEMBAHASAN}

Reaksi kimia ${ }^{(106-110)}$ adalah suatu proses dalam kehidupan yang akan menghasilkan perubahan. Katalis ${ }^{(111-115)}$ adalah suatu cara untuk mempercepat suatu kerja dari reaksi. Katalis ${ }^{(116-120)}$ dan reaksi kimia ${ }^{(121-125)}$ sangat berkaitan erat. Hal tersebut karena reaksi kimia ${ }^{(126-130)}$ membutuhkan katalis untuk mempercepat reaksi untuk membentuk hal yang baru. Tujuan 
eksperimen ini adalah untuk menguji katalitik ${ }^{(131-135)}$. Uji coba ini di lakukan dengan menggunakan daun jambu biji.

Daun jambu biji ${ }^{(136-140)}$ banyak digunakan dalam penyembuhan terutama pada penyembuhan sakit perut atau diare ${ }^{(141-145)}$ atau juga dalam penyembuhan kulit. Disini dilakukan uji coba apakah benar daun jambu biji ${ }^{(146-150)}$ dapat menyembuhkan sakit. Percobaan ini dilakukan dengan cara, ambil pisau, sendok, gelas, dan 7 helai jambu biji. Daun jambu biji ini kita haluskan, guna dihaluskan agar kita mendapat sari pati. Pada saat menghaluskan daun jambu biji kita masukkan aqua agar lebih mudah dalam mendapatkan sari patinya.

Selanjutnya, setelah sari patinya kita dapat, kita minum pelan-pelan dengan sendok. Daun jambu biji ini kita minum 2 hari, dalam sehari kita minum 3 kali. Setelah minum sari pati tersebut dapat menurukan dan menghilangkan rasa sakit perut. Kenyataan nya setelah di uji coba hal itu ternyata benar. Hal ini karena ada kandungan zat yang ada dalam daun jambu biji. Namun apabila sakitnya belum sembuh juga kita dapat meneruskannya.

Di dalam daun jambu biji, terdapat tanin, flavonoiddan juga zat guercetin glycoside. Terdapatnya tannin ini membuat pori-pori usus tertutup sehingga dalam pembuangan menjadi baik kembali. Didalam daun jambu biji memiliki antibakteri yang bagus dan kuat untuk mencegah bakteri tumbuh diakibatkan diare tersebut. Sehingga daun jambu biji ini baik kita konsumsi saat kita mengalami diare. Hal ini sudah di ujikan oleh salah satu ibu yang ada di Sidikalang, Sumatera Utara. Efek dari daun jambu adalah setiap sekali pemakaian rasa sakit semakin menghilang. 


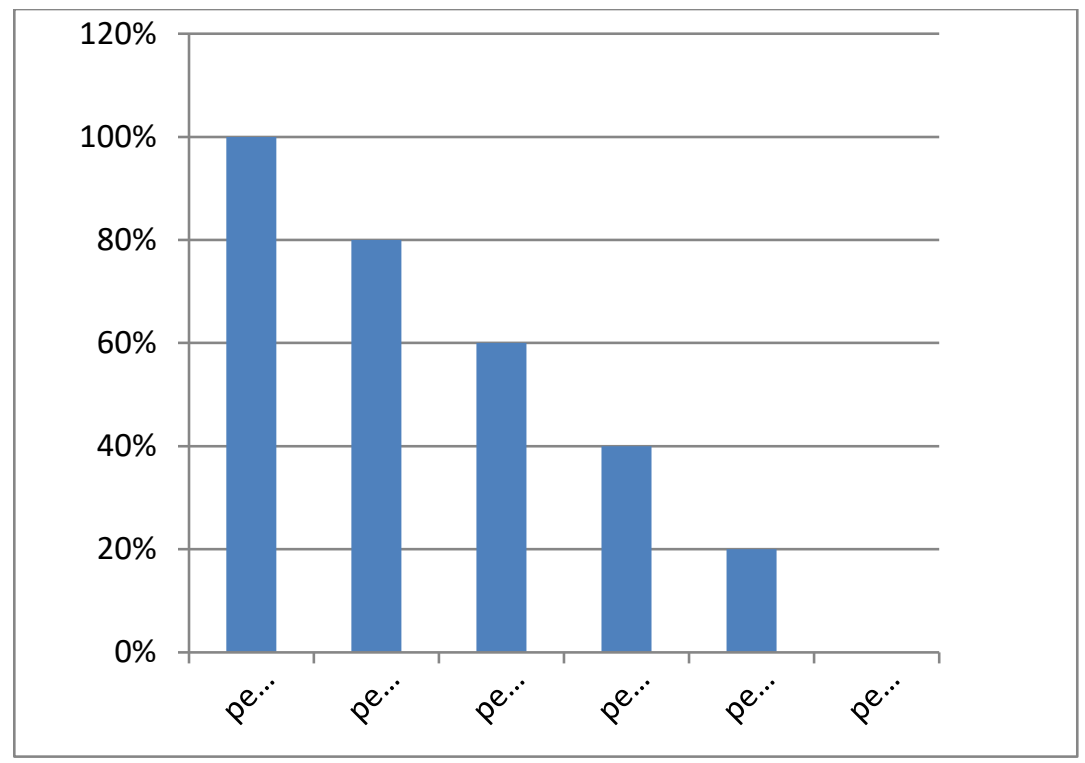

\section{KESIMPULAN}

Ekstrasi dibuat dengan cara tumbukan / menghaluskan daun jambu biji. Ekstraksi ini dapat menyembuhkan diare atau sakit perut. Tetapi bukan hanya itu saja, daun jambu biji ini banyak manfaatnya bagi kehidupan kita. Pemakaian atau peminuman ekstrak daun jambu biji ini biasanya hanya dilakukan enam kali peminuman dalam waktu dua hari. Namun apa bila belum sembuh juga maka dapat kita lanjutkan atau segara bawa ke rumah sakit. Ekstrak daun jambu biji ini mengandung zat flavonoid ${ }^{(34)}$, zat guercetun glycoside serta tanin. Tanin ini lah yang sangat bekerja karena taninlah yang menutup pori-pori yang terbuka di usus. 


\section{REFERENSI}

[1]Charlena, Purwaningsih,Henny, Rosdiana,Tina. 2008. PENCIRIAN DAN UJI AKTIVITAS KATALITIK ZEOLIT ALAM TERAKTIVASI. Jurnal Riset Kimia. Vol 1, No 2.

[2]Astiti Asih, I. A. R., Adi Setiawan, I M. 2008. SENYAWA GOLONGAN FLAVONOID PADA EKSTRAK n-BUTANOL KULIT BATANG BUNGUR (Lagerstroemia speciosa Pers.). Journal of Chemistry. Vol. 2 , No. 2.

[3]Malangngi, Liberty, Sangi, Meiske, Paendong, Jessy . 2012. Penentuan Kandungan Tanin dan Uji Aktivitas Antioksidan Ekstrak Biji Buah Alpukat (Persea americana Mill.). JURNAL MIPA UNSRAT ONLIN. Vol 1, No 1.

[4]Kusnaryo, Radya Purna Wijaya, Ali Altway,. 2008. ANALISA TRANSFER MASSA DISERTAI REAKSI KIMIA PADA ABSORPSI CO2. Teknik Kimia. Vol 2, No 2.

[5]Pangumpia, Sri Wahyuni ( manado state university ), Gugule, Sanusi, Karundeng, A. Evelin. 2014. Pembelajaran Paparan Konsep Matematika pada Materi Persamaan Reaksi Kimia di SMA Frater Don Bosco Manado. JSME MIPA UNIMA. Vol 2, No 2.

[6]Darma Santi. 2013. MODIFIKASI ZEOLIT ALAM SEBAGAI KATALIS DAN UJI AKTIVITAS KATALIS DALAM REAKSI HIDRORENGKAH MINYAK KULIT JAMBU METE (ANACARDIUM OCCIDENTALE) MENJADI BIOGASOLINE DAN BIODIESEL.Vol.5, No.2

[7]Amaliah, Siti. 2010. HUBUNGAN SANITASI LINGKUNGAN DAN FAKTOR BUDAYA DENGAN KEJADIAN DIARE PADA ANAK BALITA DI DESA TORIYO KECAMATAN BENDOSARI KABUPATEN SUKOHARJO. PROSIDING SEMINAR NASIONAL. Vol 1, No 1

[8]Sayono, U, Nurullita, M, Suryani. 2010. PENGARUH KONSENTRASI FLAVONOID DALAM EKSTRAK AKAR TUBA (Derris eliptica) 
TERHADAP KEMATIAN LARVA Aedes aegypti. JURNAL KESEHATAN MASYARAKAT INDONESIA. Vol 6, No 1

[9]DINIATIK, SOEMARDY, EDDY, INDRI, KHANINA. 2007. PERBANDINGAN KADAR FLAVONOID TOTAL DAN TANIN TOTAL PADA TEH HIJAU DAN TEH HITAM Camellia siniensis (L.) O.K. PHARMACY. Vol 5, No 3

[10]Rosidah, Afizia, Wila Mahita. 2012. POTENSI EKSTRAK DAUN JAMBU BIJI SEBAGAI ANTIBAKTERIAL UNTUK MENANGGULANGI SERANGAN BAKTERI AEROMONAS HYDROPHILA PADA IKAN GURAME (Osphronemus Gouramy lacepede). Jurnal Akuatika. Vol 3, No 1

[11] Febriani, S. S., Yolanda, T., Arianti, V. A., \& Zainul, R. (2018, October 12). A Review Solid Stated : Principles and Methode. https://doi.org/10.31227/osf.io/7us4x

[12] Febriani, S. S., Yolanda, T., Arianti, V. A., \& Zainul, R. (2018, October 12). A Review Solid Stated : Principles and Methode. https://doi.org/10.31227/osf.io/7us4x

[13] Dinata, A. A., Rosyadi, A. M., Hamid, S., \& Zainul, R. (2018, October 15). A Review CHEMICAL VAPOR DEPOSITION : PROCESS AND APPLICATION. https://doi.org/10.31227/osf.io/yfeau

[14] Syafei, N. (2018) "Riset Material ANALISA FENOMENA KOROSI PELAT PIPA BAJA KARBON API 5L-X65 DALAM LARUTAN 7900 ML AIR LAUT DAN 100 ML AMONIAK PADA KONDISI GAS CO2 DAN H2S JENUH PADA SUHU RUANG.”, EKSAKTA: Berkala Ilmiah Bidang MIPA, 19(1), pp. 7-13. doi:

10.24036/eksakta/vol19-iss1/83

[15] Zainul, R., \& Prima, C. B. (2018, December 9). TEKNOLOGI MATERIAL MAJU Prinsip Dasar dan Aspek Rekayasa. https://doi.org/10.31227/osf.io/p63wc

[16] Zainul, R. (2019, January 15). f. https://doi.org/10.31227/osf.io/75pdj

[17] Liza, Y. M., Yasin, R. C., Maidani, S. S., \& Zainul, R. (2018, October 9). SOL GEL : PRINCIPLE AND TECHNIQUE (A REVIEW). https://doi.org/10.31227/osf.io/2cuh8 
[18] Chairi, I., E., \& Zainul, R. (2018, September 19). Pengembangan LKS dengan Pendekatan Saintifik Berbasis Discovery Learning Pada Materi Hukum Dasar Kimia untuk Pembelajaran Kelas X SMA/MA. https://doi.org/10.31227/osf.io/xnbtv

[19] Zainul, R. (2018, August 16). Design and Modification of Copper Oxide Electrodes for Improving Conversion Coefficient Indoors Lights (PVCell) Photocells. https://doi.org/10.31227/osf.io/pgn84

[20] Hidayani, T. (2018) “GRAFTING POLIPROPILENA DENGAN MALEAT ANHIDRIDA SEBAGAI PENGIKAT SILANG DENGAN INISIATOR BENZOIL PEROKSIDA", EKSAKTA: Berkala Ilmiah Bidang MIPA, 19(1), pp. 56-62. doi: 10.24036/eksakta/vol19-iss1/127

[21] Joebaedi, K. (2018) "MODEL STAR(1;1) PADA DATA PRODUKTIVITAS TEH”, EKSAKTA: Berkala Ilmiah Bidang MIPA, 19(1), pp. 35-38. doi: 10.24036/eksakta/vol19-iss1/118.

[22] Dinata, M. and Soehardi, F. (2018) "Factor Analysis of Physics Chemistry Waters that Affects Damage Safety Cliff on the Outskirts of River Siak", EKSAKTA: Berkala Ilmiah Bidang MIPA, 19(2), pp. 4649. doi: 10.24036/eksakta/vol19-iss2/143.

[23] Horiza, H., Azhar, M. and Efendi, J. (2017) "EKSTRAKSI DAN KARAKTERISASI INULIN DARI UMBI DAHLIA (Dahlia sp.L) SEGAR DAN DISIMPAN", EKSAKTA: Berkala Ilmiah Bidang MIPA, 18(01), pp. 31-39. doi: 10.24036/eksakta/vol18-iss01/14.

[24] Sari, A. (2017) "POTENSI ANTIOKSIDAN ALAMI PADA EKSTRAK DAUN JAMBLANG (Syzigium cumini (L.) Skeels)", EKSAKTA: Berkala Ilmiah Bidang MIPA, 18(02), pp. 107112. doi: 10.24036/eksakta/vol18-iss02/61.

[25] Sumarmin, R. (2018) "Pengaruh Ekstrak Kulit Buah Manggis (Garcinia mangostana L.) terhadap Histologis Pankreas Mencit (Mus musculus L. Swiss Webster) yang Diinduksi Sukrosa”, EKSAKTA: Berkala Ilmiah Bidang MIPA, 19(1), pp. 100-112. doi: 10.24036/eksakta/vol19iss $1 / 123$.

[26] Rizki Saputra, M. and Sumarmin, R. (2018) "PENGARUH EKSTRAK DAUN SIRIH MERAH (Piper crocatum Ruiz \& Pav.) TERHADAP 
GLUKOSA DARAH MENCIT (Mus musculus L.) JANTAN YANG DIINDUKSI SUKROSA", EKSAKTA: Berkala Ilmiah Bidang MIPA, 19(1), pp. 43-55. doi: 10.24036/eksakta/vol19-iss1/124.

[27] Sanjaya, H. (2017) "DEGRADASI METHYLENE BLUE MENGGUNAKAN KATALIS ZnO-PEG DENGAN METODE FOTOSONOLISIS", EKSAKTA: Berkala Ilmiah Bidang MIPA, 18(02), pp. 21-29. doi: 10.24036/eksakta/vol18-iss02/45.

[28] Iskandar, I., Horiza, H. and Fauzi, N. (2017) "EFEKTIVITAS BUBUK BIJI PEPAYA (Carica Papaya Linnaeaus) SEBAGAI LARVASIDA ALAMI TERHADAP KEMATIAN LARVA AEDES AEGYPTY TAHUN 2015", EKSAKTA: Berkala Ilmiah Bidang MIPA, 18(01), pp. 12-18. doi: 10.24036/eksakta/vol18-iss01/12

[29] Prabowo, H. (2018) "PENYELIDIKAN KELAYAKAN KIMIA DAN PENYEBARAN CADANGAN PASIR BESI DAERAH TIKU KABUPATEN AGAM UNTUK BAHAN BAKU SEMEN PADA PT. SEMEN PADANG", EKSAKTA: Berkala Ilmiah Bidang MIPA, 19(1), pp. 39-42. doi: 10.24036/eksakta/vol19-iss1/121.

[30] Parbuntari, H., Prestica, Y., Gunawan, R., Nurman, M. and Adella, F. (2018) "Preliminary Phytochemical Screening (Qualitative Analysis) of Cacao Leaves (Theobroma cacao L.)", EKSAKTA: Berkala Ilmiah Bidang MIPA, 19(2), pp. 40-45. doi: 10.24036/eksakta/vol19-iss2/142.

[31] Rizki Saputra M, Sumarmin R. PENGARUH EKSTRAK DAUN SIRIH MERAH (Piper crocatum Ruiz \& Pav.) TERHADAP GLUKOSA DARAH MENCIT (Mus musculus L.) JANTAN YANG DIINDUKSI SUKROSA. EKSAKTA [Internet]. 25Apr.2018 [cited 18Apr.2019];19(1):43-5. Available from: http://eksakta.ppj.unp.ac.id/index.php/eksakta/article/view/124

[32] Cover C. Cover Eksakta Berkala Ilmiah Bidang MIPA Volume 18 No 2 Bulan Oktober 2017. EKSAKTA [Internet]. 30Nov.2017 [cited 18Apr.2019];18(02). Available from: http://eksakta.ppj.unp.ac.id/index.php/eksakta/article/view/39

[33] Suryelita S, Etika SB, Kurnia NS. ISOLASI DAN KARAKTERISASI SENYAWA STEROID DARI DAUN CEMARA NATAL (Cupressus funebris Endl.). EKSAKTA [Internet]. 5May2017 [cited 
18Apr.2019];18(01):86-4. Available from:

http://eksakta.ppj.unp.ac.id/index.php/eksakta/article/view/23

[34] Ramli R, Jonuarti R, Hartono A. ANALISIS STRUKTUR NANO

DARI LAPISAN TIPIS COBALT FERRITE YANG DIPREPARASI

DENGAN METODE SPUTTERING. EKSAKTA [Internet]. 28Apr.2017 [cited 18Apr.2019];18(01):46-3. Available from: http://eksakta.ppj.unp.ac.id/index.php/eksakta/article/view/16

[35] Iryani I, Iswendi I, Katrina IT. UJI AKTIVITAS ANTI DIABETES MELLITUS SENYAWA METABOLIT SEKUNDER FRAKSI AIR DARI BERAS KETAN HITAM ( Oryza satival. Var glutinosa) PADA MENCIT PUTIH. EKSAKTA [Internet]. 28Apr.2017 [cited 18Apr.2019];18(01):54-0. Available from:

http://eksakta.ppj.unp.ac.id/index.php/eksakta/article/view/17

[36] Zainul, R. (2018, August 16). Design and Modification of Copper Oxide Electrodes for Improving Conversion Coefficient Indoors Lights (PV-Cell) Photocells. https://doi.org/10.31227/osf.io/pgn84

[37] Zainul, R. (2018, August 16). Determination of the half-life and the quantum yield of $\mathrm{ZnO}$ semiconductor photocatalyst in humic acid. https://doi.org/10.31227/osf.io/e8a9x

[38] Maryudi, Maryudi, Hisyam, Anwaruddin. 2013. KINETIKA REAKSI KHROM DAN KAPUR PADAM PADA PENGOLAHAN LIMBAH PENYAMAKAN KULIT SECARA BATCH. SPEKTRUM INDUSTRI. Vol 11, No 1

[39] Agus Wibowo, Agus Wibowo. 2010. LAJU REAKSI PENCAMPURAN MINYAK JARAK DAN AIR PADA HYDROGEN REFORMER MENGGUNAKAN PEMANAS DAN KATALIS.

Prosiding Seminar Nasional Sains Dan Teknologi Fakultas Teknik. Vol 1 , No 1

[40] AZIZ, SANDRA ARIFIN, GHULAMAHDI, MUNIF. 2011. Red Guava Leaf Harvesting Impact on Flavonoid Optimation in Different Growth Phases. HAYATI Journal of Bioscience. Vol 18, No 2

[41] Zainul, R. (2018, August 16). Effect of Temperature and Particle Motion against the ability of $\mathrm{ZnO}$ Semiconductor Photocatalyst in Humic Acid. https://doi.org/10.31227/osf.io/wnygb 
[42] Zainul, R., Oktavia, B., Nasra, E., Arianti, V. A., Fatimah, P., Liza, Y. M., \& Setiadi, T. (2018, December 13). Studi Pengembangan dan Efektivitas Model Penulisan Karya Ilmiah berbasis Online Data dengan menggunakan Aplikasi Endnote bagi Guru-guru MGMP Kimia Kota Padangpanjang. https://doi.org/10.31227/osf.io/2gcq7

[43] M., Sanjaya, H., \& Zainul, R. (2018, August 11). Characterization of napa soil and adsorption of $\mathrm{Pb}$ (II) from aqueous solutions using on column method. https://doi.org/10.31227/osf.io/t8fh9

[44] Zainul, R., \& Prima, C. B. (2018, December 9). TEKNOLOGI MATERIAL MAJU Prinsip Dasar dan Aspek Rekayasa. https://doi.org/10.31227/osf.io/p63w

[45] Zainul, R., Oktavia, B., G., \& putra, a. (2018, August 16). Pengenalan Dan Pengembangan E-Modul Bagi Guru- Guru Anggota MGMP Kimia Dan Biologi Kota Padang Panjang. https://doi.org/10.31227/osf.io/yhau2

[46] Aumi, V., M., \& Zainul, R. (2018, August 25). Pengembangan Bentuk Lembar Kerja Siswa (LKS) untuk Aktivitas Kelas dan Laboratorium Berbasis Inkuiri Terbimbing pada Pokok Bahasan Laju Reaksi. https://doi.org/10.31227/osf.io/7rszp

[47] Zainul, R., \& Prima, C. B. (2018, November 11). Desain Geometri Sel PV. https://doi.org/10.31227/osf.io/7n8t4

[48] Guci, S. R. F., Zainul, R., \& Azhar, M. (2018, September 19). PENGEMBANGAN MEDIA PEMBELAJARAN BERBASIS TIGA LEVEL REPRESENTASI MENGGUNAKAN PREZI PADA MATERI KESETIMBANGAN KIMIA KELAS XI SMA/MA. https://doi.org/10.31227/osf.io/n7jk

[49] Lubis, A. P., \& Zainul, R. (2018, November 5). Interaksi Molekuler Amonium Hidroksida. https://doi.org/10.31227/osf.io/jht3b

[50] Putri, G. A., H., \& Zainul, R. (2018, September 25). DEVELOPMENT OF PERIODIC TABLE INTERACTIVE INSTRUCTIONAL MULTIMEDIA IN CHEMISTRY LESSON FOR Xth GRADE SMA / MA. https://doi.org/10.31227/osf.io/2hsme 
[51] Dwynda, I., \& Zainul, R. (2018, November 19). Boric Acid (H3 (BO3): Recognize The Molecular Interactions in Solutions. https://doi.org/10.31227/osf.io/6wead

[52] Artika, P. I., \& Zainul, R. (2018, November 19). Potassium Bromide (KBr): Transformasi ionik dan sifat temodinamika dalam Larutan. https://doi.org/10.31227/osf.io/a5hyz

[53] Sari, M., \& Zainul, R. (2018, November 19). Kalium Dikromat (K2Cr2O7) Spektroskopi dan Transpor K2Cr2O7. https://doi.org/10.31227/osf.io/w92je

[54] Zainul, R. (2018, December 24). Model Reaktor Deksagonal. https://doi.org/10.31227/osf.io/2td7n

[55] Yanti, C. F., \& Zainul, R. (2018, December 2). A Review Ba (OH)2 : Transpor Ionik pada Barium Hidroksida di dalam Air dengan Konsep Termodinamika. https://doi.org/10.31227/osf.io/fsbq3

[56] Yulis, R., Zainul, R., \& M. (2018, December 10). DESAIN DAN KARAKTERISASI SEL SURYA SISTEM ELEKTRODA TEMBAGA (I) OKSIDA (Cu2O/Al) MODEL PIPA PADA LARUTAN NATRIUM SULFAT (Na2SO4). https://doi.org/10.31227/osf.io/m43js

[57] Putri, G. E., Arief, S., Jamarun, N., Gusti, F. R., \& Zainul, R. (2018, December 10). Microstuctural Analysis and Optical Properties of Nanocrystalline Cerium Oxides Synthesized by Precipitation Method. https://doi.org/10.31227/osf.io/qcz4y

[58] Zainul, R. (2018, December 24). Model Reaktor Deksagonal. https://doi.org/10.31227/osf.io/2td7n

[59] Rahmadhanty, S., \& Zainul, R. (2018, December 24). DESIGN OF HUMAT ACID SOLID SOLUTION REACTOR THROUGH PHOTOTRANSFORMATION OF COPPER OXIDE $(\mathrm{CuO})$ SEMICONDUCTOR PLATE. https://doi.org/10.31227/osf.io/yhd9x

[60] Husna, A. D., \& Zainul, R. (2019, February 4). Analisis Molekular dan Karakteristik Hidrogen Sianida (HCN). https://doi.org/10.31227/osf.io/7xej9 
[61] Jumalia, R., \& Zainul, R. (2019, February 3). Natrium Karbonat : Termodinamika dan Transport Ion. https://doi.org/10.31227/osf.io/y2vq9

[62] Zainul, R. (2018, December 24). Model Reaktor Deksagonal. https://doi.org/10.31227/osf.io/2td7n

[63] Zainul, R., \& Prima, C. B. (2018, December 9). TEKNOLOGI MATERIAL MAJU Prinsip Dasar dan Aspek Rekayasa. https://doi.org/10.31227/osf.io/p63wc

[64] Aumi, V., M., \& Zainul, R. (2018, August 25). Pengembangan Bentuk Lembar Kerja Siswa (LKS) untuk Aktivitas Kelas dan Laboratorium Berbasis Inkuiri Terbimbing pada Pokok Bahasan Laju Reaksi. https://doi.org/10.31227/osf.io/7rszp

[65] Chairi, I., E., \& Zainul, R. (2018, September 19). Pengembangan LKS dengan Pendekatan Saintifik Berbasis Discovery Learning Pada Materi Hukum Dasar Kimia untuk Pembelajaran Kelas X SMA/MA. https://doi.org/10.31227/osf.io/xnbtv

[66] Sepriandi, P., E., \& Zainul, R. (2018, September 19). Pengembangan LKS Dengan Pendekatan Saintifik Berbasis Discovery Learning pada Materi Asam Basa untuk Pembelajaran Kimia Kelas XI SMA/MA. https://doi.org/10.31227/osf.io/5cb3h

[67] Desideria, S., Dj, L., \& Zainul, R. (2018, November 6). Deskripsi Keterampilan Proses Sains Peserta Didik Kelas XI IPA pada Materi Larutan Penyangga di SMAN 15 Padang. https://doi.org/10.31227/osf.io/t5q89

[68] Maypalita, F., M., \& Zainul, R. (2018, September 25). Pengaruh Penggunaan Lembar Kerja Siswa (LKS) Berbasis Inkuiri Terbimbing Pada Materi Larutan Penyangga Terhadap Hasil Belajar Siswa Kelas XI IPA SMAN 5 Padang. https://doi.org/10.31227/osf.io/j3fxc

[69] chaidir, z., Fadjria, N., A., \& Zainul, R. (2018, August 11). ISOLATION AND MOLECULAR IDENTIFICATION OF FRESHWATER MICROALGAE IN MANINJAU LAKE WEST SUMATERA. https://doi.org/10.31227/osf.io/nbcuf 
[70] Setiadi, T., \& Zainul, R. (2019, April 4). Pengembangan E-Modul Asam Basa Berbasis Discovery Learning Untuk Kelas XI SMA/MA. https://doi.org/10.31227/osf.io/ugcrk

[71] Zainul, R. (2018, December 24). Model Reaktor Deksagonal. https://doi.org/10.31227/osf.io/2td7n

[72] Dwynda, I., \& Zainul, R. (2018, November 19). Boric Acid (H3 (BO3): Recognize The Molecular Interactions in Solutions. https://doi.org/10.31227/osf.io/6wead

[73] Sari, E. S. J., \& Zainul, R. (2019, January 31). Nitrogen Triflorida (NF3) : Termodinamika dan Transpor Elektron NF3. https://doi.org/10.31227/osf.io/3nzrh

[74] Rahmadhanty, S., \& Zainul, R. (2018, December 24). DESIGN OF HUMAT ACID SOLID SOLUTION REACTOR THROUGH PHOTOTRANSFORMATION OF COPPER OXIDE $(\mathrm{CuO})$ SEMICONDUCTOR PLATE. https://doi.org/10.31227/osf.io/yhd9x

[75] Putri, G. A., H., \& Zainul, R. (2018, September 25). DEVELOPMENT OF PERIODIC TABLE INTERACTIVE INSTRUCTIONAL MULTIMEDIA IN CHEMISTRY LESSON FOR Xth GRADE SMA / MA. https://doi.org/10.31227/osf.io/2hsme

[76] Zainul, R. (2018, December 24). Prototype Reaktor Deksagonal. https://doi.org/10.31227/osf.io/d7wzk

[77] chaidir, z., Zainul, R., Nurakhbari, D., \& Salim, M. (2018, July 29). Optimization of Spirulina Platensis Culture for Antioxidant Production. https://doi.org/10.17605/OSF.IO/FD6E4

[78] Artika, P. I., \& Zainul, R. (2018, November 19). Potassium Bromide $(\mathrm{KBr})$ : Transformasi ionik dan sifat temodinamika dalam Larutan. https://doi.org/10.31227/osf.io/a5hyz

[79] Fati, N., Siregar, R. and Sujatmiko, S. (2019) “Addition Of Coleus Amboinicus, L Leaf's Extract In Ration To Percentage Of Carcass, Abdominal Fat, Liver And Heart Broiler", EKSAKTA: Berkala Ilmiah Bidang MIPA, 20(1), pp. 1-9. doi: 10.24036/eksakta/vol20-iss1/157. 
[79] Putri, D., Anika, M. and Wahyuni, W. (2019) "Bioinformatics Study Genes Encoding Enzymes Involved in the Biosynthesis of Carotenoids Line Cassava (Manihot esculenta)", EKSAKTA: Berkala Ilmiah Bidang MIPA, 20(1), pp. 10-16. doi: 10.24036/eksakta/vol20-iss1/161.

[80] Suratno, T., Rarasati, N. and Z G. (2019) "Optimization of Genetic Algorithm for Implementation Designing and Modeling in Academic Scheduling", EKSAKTA: Berkala Ilmiah Bidang MIPA, 20(1), pp. 1724. doi: 10.24036/eksakta/vol20-iss1/166.

[81] Ramalisa, Y., Febriyanti, A. and Multahadah, C. (2019) “Analysis of Non Hierarchical Bomb for Collection of Community Health Degrees in Jambi and Muaro Jambi City", EKSAKTA: Berkala Ilmiah Bidang MIPA, 20(1), pp. 25-34. doi: 10.24036/eksakta/vol20-iss1/167.

[82] Pasaribu, F., Mardia, A. and Sormin, C. (2019) "Ordinal Logistic Regression with an Application to Health Service Quality in Raden Mattaher Jambi Hospital”, EKSAKTA: Berkala Ilmiah Bidang MIPA, 20(1), pp. 35-40. doi: 10.24036/eksakta/vol20-iss1/168.

[83] Badrulfalah, B., Susanti, D., Joebaedi, K. and Kosasih, R. (2019) "Some Properties of Green's Matrix of Nonlinear Boundary Value Problem of First Order Differential”, EKSAKTA: Berkala Ilmiah Bidang MIPA, 20(1), pp. 41-47. doi: 10.24036/eksakta/vol20-iss1/173.

[84] Joebaedi, K., Susanti, D., Warwah, N., Parmikanti, K. and Badrulfalah, B. (2019) "Factors Affecting the Amount of Investment Loans in Commercial Banks with the Application of Linear Regression Analysis Methods", EKSAKTA: Berkala Ilmiah Bidang MIPA, 20(1), pp. 48-54. doi: 10.24036/eksakta/vol20-iss1/172.

[85] Suhaemi, Z., Zulkarnaini, Z., Afrijon, A. and Jefri, P. (2019) "The Study of African Leave (Vernonia amygdalina) in for Improving the Quality of Local Duck Meats of West Sumatera", EKSAKTA: Berkala Ilmiah Bidang MIPA, 20(1), pp. 55-59. doi: 10.24036/eksakta/vol20iss $1 / 174$.

[86] Afnuhazi, R. (2019) "Bivariate Analysis on Autism Therapy using Social Skills Training in SLB YPPA Padang”, EKSAKTA: Berkala Ilmiah Bidang MIPA, 20(1), pp. 60-76. doi: 10.24036/eksakta/vol20iss $1 / 175$. 
[87] Dinata, M., Fitridawati, F. and Putri, L. (2019) "The Study Trees Potential for Forest in Universitas Lancang Kuning Pekanbaru", EKSAKTA: Berkala Ilmiah Bidang MIPA, 20(1), pp. 7785. doi: 10.24036/eksakta/vol20-iss1/176.

[88] Syafei, N. (2019) "Events of corrosion phenomena on carbon steel pipes in environment of sea water and ammonia solutions due to the presence of sweet gas", EKSAKTA: Berkala Ilmiah Bidang MIPA, 20(1), pp. 86-99. doi: 10.24036/eksakta/vol20-iss1/178.

[89] Zainul, R. and Wardani, S. (2019) "The Hydrogen Generator Performance of Sandwich Designed 4/4 Al-Cu Plates", EKSAKTA: Berkala Ilmiah Bidang MIPA, 20(1), pp. 100-104. doi: 10.24036/eksakta/vol20-iss1/177.

[90] Amir, H., Akmam, A., Bavitra, B. and Azhari, M. (2017) "PENENTUAN KEDALAMAN BATUAN DASAR MENGGUNAKAN METODE GEOLISTRIK TAHANAN JENIS DENGAN MEMBANDINGKAN KONFIGURASI DIPOLE-DIPOLE DAN WENNER DI BUKIT APIT PUHUN KECAMATAN GUGUK PANJANG KOTA BUKITTINGGI", EKSAKTA: Berkala Ilmiah Bidang MIPA, 18(01), pp. 19-30. doi: 10.24036/eksakta/vol18iss01/13.

[91] Ramli, R., Jonuarti, R. and Hartono, A. (2017) “ANALISIS STRUKTUR NANO DARI LAPISAN TIPIS COBALT FERRITE YANG DIPREPARASI DENGAN METODE SPUTTERING", EKSAKTA: Berkala Ilmiah Bidang MIPA, 18(01), pp. 46-53. doi: 10.24036/eksakta/vol18-iss01/16.

[92] Handayani, D. (2017) “KARAKTERISTIK CENDAWAN DARK SEPTATE ENDOPHYTE (DSE) PADA AKAR TANAMAN JAGUNG DAN PADI", EKSAKTA: Berkala Ilmiah Bidang MIPA, 18(01), pp. 61-68. doi: 10.24036/eksakta/vol18-iss01/20.

[93] Suryelita, S., Etika, S. B. and Kurnia, N. S. (2017) "ISOLASI DAN KARAKTERISASI SENYAWA STEROID DARI DAUN CEMARA NATAL (Cupressus funebris Endl.)", EKSAKTA: Berkala Ilmiah Bidang MIPA, 18(01), pp. 86-94. doi: 10.24036/eksakta/vol18iss01/23. 
[94] Permana, D. (2017) "MODEL STOKASTIK RANTAI MARKOV EMPAT STATUS PADA PENENTUAN NILAI HIDUP PELANGGAN", EKSAKTA: Berkala Ilmiah Bidang MIPA, 18(01), pp. 78-85. doi: 10.24036/eksakta/vol18-iss01/22.

[95] Handayani, D. (2017) "KARAKTERISTIK CENDAWAN DARK SEPTATE ENDOPHYTE (DSE) PADA AKAR TANAMAN JAGUNG DAN PADI", EKSAKTA: Berkala Ilmiah Bidang MIPA, 18(01), pp. 61-68. doi: 10.24036/eksakta/vol18-iss01/20.

[96] Vauzia, V. and Gusmira, E. (2018) "The Response of Jabon Seeds Germination (Anthocephalus cadamba (Roxb.)Miq.) against the Duration of Combustion and Illumination", EKSAKTA: Berkala Ilmiah Bidang MIPA, 19(2), pp. 80-87. doi: 10.24036/eksakta/vol19-iss2/154.

[97] Yanuar, F., Tillah, M. and Devianto, D. (2018) "Modeling of Human Development Index Using Ridge Regression Method", EKSAKTA: Berkala Ilmiah Bidang MIPA, 19(2), pp. 1-11. doi: 10.24036/eksakta/vol19-iss2/134.

[98] Enjelina, W., Mansyurdin, M. and Meideliza, T. (2018) "Analysis of Nepenthes Hybrids in Bukik Taratak West Sumatra by RAPD Technique", EKSAKTA: Berkala Ilmiah Bidang MIPA, 19(2), pp. 1220. doi: 10.24036/eksakta/vol19-iss2/137.

[99] Syafei, N., Hidayat, D., Emilliano, E. and Men, L. (2018) "Analysis Cracking Corrosion on Carbon Steel Pipes API 5L-X65 In Solution $7700 \mathrm{ml}$ Aquades, $250 \mathrm{ml}$ Acetic Acid and $50 \mathrm{ml}$ Ammonia with Gas $\mathrm{CO} 2$ and $\mathrm{H} 2 \mathrm{~S}$ in Saturation Condition", EKSAKTA: Berkala Ilmiah Bidang MIPA, 19(2), pp. 21-31. doi: 10.24036/eksakta/vol19-iss2/138.

[100] Dinata, M. and Soehardi, F. (2018) "Factor Analysis of Physics Chemistry Waters that Affects Damage Safety Cliff on the Outskirts of River Siak", EKSAKTA: Berkala Ilmiah Bidang MIPA, 19(2), pp. 46-49. doi: 10.24036/eksakta/vol19-iss2/143.

[101] Badrulfalah, B., Irianingsih, I. and Joebaedi, K. (2018) "Some Operations on Mixed Monotone Operator in Banach Spaces", EKSAKTA: Berkala Ilmiah Bidang MIPA, 19(2), pp. 57-61. doi: 10.24036/eksakta/vol19-iss2/150.

[102] Sofyanita, S. and Octaria, Z. (2018) "Fenthion Compound Degradation in the Pesticide Bayleton $500 \mathrm{ec}$ in Sonolysis, Ozonolysis and Sonozolysis with Addition of TiO2-anatase", EKSAKTA: Berkala 
Ilmiah Bidang MIPA, 19(2), pp. 70-79. doi: 10.24036/eksakta/vol19iss $2 / 153$.

[103] Putri, D., Fifendy, M. and putri, M. (2018) "DIVERSITAS BAKTERI ENDOFIT PADA DAUN MUDA DAN TUA TUMBUHAN ANDALEH (Morus macroura miq.)", EKSAKTA: Berkala Ilmiah Bidang MIPA, 19(1), pp. 125-130. doi: 10.24036/eksakta/vol19iss $1 / 122$.

[104] Hidayat, D. (2018) “ANALISIS RESPON PENGONTROL ON-OFF PADA KENDALI UMPAN BALIK SISTEM FISIS ELEKTRONIK”, EKSAKTA: Berkala Ilmiah Bidang MIPA, 19(1), pp. 118-124. doi: 10.24036/eksakta/vol19-iss1/119.

[105] Rizal, Y. (2018) "DIAGONALISASI BENTUK KUADRATIK IRISAN KERUCUT”, EKSAKTA: Berkala Ilmiah Bidang MIPA, 19(1), pp. 83-90. doi: 10.24036/eksakta/vol19-iss1/132.

[106] Badrulfalah, B. (2018) "SUB RUANG TUTUP TOPOLOGI HASIL KALI RUANG METRIK KERUCUT”, EKSAKTA: Berkala Ilmiah Bidang MIPA, 19(1), pp. 63-67. doi: 10.24036/eksakta/vol19iss $1 / 128$.

[107] Hidayani, T. (2018) "GRAFTING POLIPROPILENA DENGAN MALEAT ANHIDRIDA SEBAGAI PENGIKAT SILANG DENGAN INISIATOR BENZOIL PEROKSIDA", EKSAKTA: Berkala Ilmiah Bidang MIPA, 19(1), pp. 56-62. doi: 10.24036/eksakta/vol19-iss1/127.

[108] Prabowo, H. (2018) "PENYELIDIKAN KELAYAKAN KIMIA DAN PENYEBARAN CADANGAN PASIR BESI DAERAH TIKU KABUPATEN AGAM UNTUK BAHAN BAKU SEMEN PADA PT. SEMEN PADANG”, EKSAKTA: Berkala Ilmiah Bidang MIPA, 19(1), pp. 39-42. doi: 10.24036/eksakta/vol19-iss1/121.

[109] Syafei, N. (2018) "Riset Material ANALISA FENOMENA KOROSI PELAT PIPA BAJA KARBON API 5L-X65 DALAM LARUTAN 7900 ML AIR LAUT DAN 100 ML AMONIAK PADA KONDISI GAS CO2 DAN H2S JENUH PADA SUHU RUANG.”, EKSAKTA: Berkala Ilmiah Bidang MIPA, 19(1), pp. 7-13. doi: 10.24036/eksakta/vol19-iss1/83. 
[110] Chatri, M., Mansyurdin, M., Bakhtiar, A. and Adnadi, P. (2017) "PERBANDINGAN KOMPONEN MINYAK ATSIRI ANTARA DAUN MUDA DAN DAUN DEWASA PADA HYPTIS SUAVEOLENS (L.)POIT", EKSAKTA: Berkala Ilmiah Bidang MIPA, 18(02), pp. 1-12. doi: 10.24036/eksakta/vol18-iss02/41.

[111] Ningsih, S. K. (2017) "SINTESIS DAN KARAKTERISASI NANOPARTIKEL ZnO DOPED Cu2+ MELALUI METODA SOLGEL", EKSAKTA: Berkala Ilmiah Bidang MIPA, 18(02), pp. 39-51. doi: 10.24036/eksakta/vol18-iss02/51.

[112] Samah, S. (2017) “KARAKTERISASI PLASTIK BIODEGRADABEL DARI LDPE-g-MA DAN PATI TANDAN KOSONG SAWIT", EKSAKTA: Berkala Ilmiah Bidang MIPA, 18(02), pp. 30-38. doi: 10.24036/eksakta/vol18-iss02/48.

[113] Saiya, A. (2017) “ANALISIS RESIDU KLORPIRIFOS DALAM SAYURAN KUBIS DENGAN METODE HPLC DI BEBERAPA PASAR TRADISIONAL DI SULAWESI UTARA", EKSAKTA: Berkala Ilmiah Bidang MIPA, 18(02), pp. 77-85. doi: 10.24036/eksakta/vol18-iss02/57.

[114] Hartono, A. (2017) “APLIKASI SENSOR PVDF UNTUK PENGUKURAN PERGESERAN SUDUT”, EKSAKTA: Berkala Ilmiah Bidang MIPA, 18(02), pp. 100-106. doi: 10.24036/eksakta/vol18-iss02/60.

[115] Syafei, N. (2017) “ANALISA FENOMENA KOROSI PELAT PIPA BAJA KARBON API 5L-X65 DALAM LARUTAN 250 ML ASAM ASETAT DAN 4750 ML AQUADES PADA KONDISI GAS CO2 DAN H2S JENUH PADA SUHU RUANG", EKSAKTA: Berkala Ilmiah Bidang MIPA, 18(02), pp. 113-120. doi: 10.24036/eksakta/vol18-iss02/63.

[116] Murni, D. (2017) "PERBANDINGAN DAN KARAKTERISTIK BEBERAPATES KONVERGENSI PADA DERET TAK HINGGA", EKSAKTA: Berkala Ilmiah Bidang MIPA, 18(02), pp. 146-157. doi: 10.24036/eksakta/vol18-iss02/71.

[117] Sudrajat, R. (2017) “TINJAUAN TENTANG KETERKAITAN PARAMETER DENGAN MODEL REGRESI MULTIVARIAT PADA KOLAM IKAN TERTUTUP”, EKSAKTA: Berkala Ilmiah 
Bidang MIPA, 18(02), pp. 158-163. doi: 10.24036/eksakta/vol18iss02/72.

[118] Setianto, S. (2017) “ANALISA KUANTITATIF CAMPURAN SENYAWA OKSIDA SEBAGAI DASAR IDENTIFIKASI KANDUNGAN BAHAN SUMBER DAYA ALAM Studi Kasus : Kandungan Mineral pada Pasir Besi di Pesisir Pantai Selatan, Jawa Barat", EKSAKTA: Berkala Ilmiah Bidang MIPA, 18(02), pp. 173177. doi: 10.24036/eksakta/vol18-iss02/74.

[119] Permana, D. (2017) "MODEL STOKASTIK RANTAI MARKOV EMPAT STATUS PADA PENENTUAN NILAI HIDUP PELANGGAN", EKSAKTA: Berkala Ilmiah Bidang MIPA, 18(01), pp. 78-85. doi: 10.24036/eksakta/vol18-iss01/22.

[120] Amir, H., Akmam, A., Bavitra, B. and Azhari, M. (2017) "PENENTUAN KEDALAMAN BATUAN DASAR MENGGUNAKAN METODE GEOLISTRIK TAHANAN JENIS DENGAN MEMBANDINGKAN KONFIGURASI DIPOLEDIPOLE DAN WENNER DI BUKIT APIT PUHUN KECAMATAN GUGUK PANJANG KOTA BUKITTINGGI", EKSAKTA: Berkala Ilmiah Bidang MIPA, 18(01), pp. 19-30. doi: 10.24036/eksakta/vol18iss01/13.

[121] Iskandar, I., Horiza, H. and Fauzi, N. (2017) "EFEKTIVITAS BUBUK BIJI PEPAYA (Carica Papaya Linnaeaus) SEBAGAI LARVASIDA ALAMI TERHADAP KEMATIAN LARVA AEDES AEGYPTY TAHUN 2015", EKSAKTA: Berkala Ilmiah Bidang MIPA, 18(01), pp. 12-18. doi: 10.24036/eksakta/vol18-iss01/12.

[122] Enjelina, W., Mansyurdin, M. and Meideliza, T. (2018) “Analysis of Nepenthes Hybrids in Bukik Taratak West Sumatra by RAPD Technique”, EKSAKTA: Berkala Ilmiah Bidang MIPA, 19(2), pp. 1220. doi: 10.24036/eksakta/vol19-iss2/137.

[123] Santoso, B., Setianto, S., Hasanah, M., Wijatmoko, B., Supriyana, E. and Mohammad, H. (2018) "Mitigation of Land Movement using Self Potential Method in Ling-Anjung Region Sumedang Regency", EKSAKTA: Berkala Ilmiah Bidang MIPA, 19(2), pp. 3239. doi: 10.24036/eksakta/vol19-iss2/141. 
[124] Sofyanita, S. and Octaria, Z. (2018) "Fenthion Compound

Degradation in the Pesticide Bayleton $500 \mathrm{ec}$ in Sonolysis, Ozonolysis and Sonozolysis with Addition of TiO2-anatase", EKSAKTA: Berkala Ilmiah Bidang MIPA, 19(2), pp. 70-79. doi: 10.24036/eksakta/vol19iss $2 / 153$.

[125] Vauzia, V. and Gusmira, E. (2018) "The Response of Jabon Seeds Germination (Anthocephalus cadamba (Roxb.)Miq.) against the Duration of Combustion and Illumination", EKSAKTA: Berkala Ilmiah Bidang MIPA, 19(2), pp. 80-87. doi: 10.24036/eksakta/vol19-iss2/154.

[126] Badrulfalah, B., Irianingsih, I. and Joebaedi, K. (2018) "Some Operations on Mixed Monotone Operator in Banach Spaces", EKSAKTA: Berkala Ilmiah Bidang MIPA, 19(2), pp. 57-61. doi: 10.24036/eksakta/vol19-iss2/150.

[127] Harahap, F. and Lubis, L. (2018) "Analysis of Heavy Metals Distribution in the River Town of Hamasaki's Rod Padangsidimpuan", EKSAKTA: Berkala Ilmiah Bidang MIPA, 19(2), pp. 50-56. doi: 10.24036/eksakta/vol19-iss2/149.

[128] Nasir, M. (2017) "PENGARUH WAKTU HIGH ENERGY MILLING TERHADAP KARAKTERISTIK NANOKAOLIN CAPKALA ASAL KALIMANTAN BARAT", EKSAKTA: Berkala Ilmiah Bidang MIPA, 18(02), pp. 200-209. doi: 10.24036/eksakta/vol18-iss02/78.

[129] Tutuarima, T. (2017) "SIFAT FISIK DAN KIMIA MARMALADE JERUK KALAMANSI (Citrus microcarpa) : KAJIAN KONSENTRASI PEKTIN DAN SUKROSA Physical and Chemical Properties of Marmalade Citrus of Calamondin (Citrus microcarpa) : Study of Pectin and Sucrose Concentrations", EKSAKTA: Berkala Ilmiah Bidang MIPA, 18(02), pp. 164-172. doi: 10.24036/eksakta/vol18-iss02/73.

[130] Samah, S. (2017) "KARAKTERISASI PLASTIK BIODEGRADABEL DARI LDPE-g-MA DAN PATI TANDAN KOSONG SAWIT", EKSAKTA: Berkala Ilmiah Bidang MIPA, 18(02), pp. 30-38. doi: 10.24036/eksakta/vol18-iss02/48.

[131] Santo, John de.2000.Revolusi Sains Membingkai Paradigma Ekonomi. Jurnal Humaniora.Vol 12, No 3

[132] Harsanto, Prayanto Widyo. 2011.Fotografi: Sains, Teknologi, Seni, dan Industri. Nirmana.Vol 13, No 1

[133] Wahyudi, Henricus Ganjar, -, Sarto, , , Hadiman.2010. STUDI PEMANFAATAN BUNGKIL JARAK PAGAR (JATROPHA CURCAS L.) SEBAGAI BAHAN BAKU PESTISIDA ALAMI; STUDY ON CAKE FROM JATROPHA CURCAS LINN USED AS 
NATURAL PESTICIDE MAIN SUBSTANCE. Jurnal Sistem Teknik.Vol 1

[134] DWI ADI SUNARTO, NURINDAH . 2009. Peran Insektisida Botani Ekstrak Biji Mimba untuk Konservasi Musuh Alami dalam Pengelolaan Serangga Hama Kapas. Jurnal Entomologi Indonesia.Vol 6, No 1

[135] Hartati, Sri, Zuliarso, Eri.2008. Aplikasi Pengolah Bahasa Alami untuk Query Basisdata XML.Dinamik - Jurnal Teknologi Informasi.Vol 13, No 2

[136] Ariyani, Farida, Haryati, Sakinah, Wahyuni, Mita, Wisudo, Sugeng Hari.2007. Penggunaan Ekstrak Bahan Alami Untuk Menghambat Infestasi Lalat Selama Penjemuran Ikan Jambal Asin. Jurnal Pascapanen dan Bioteknologi Kelautan dan Perikanan.Vol 2, No 2

[137] Bisatya W., MAER,.2012. EFISIENSI STRUKTUR ALAMI, ANTARA BENTUK DAN SISTEM STRUKTUR DIMENSI (Jurnal Teknik Arsitektur).Vol 39, No 2

[138] BINDRIYA RADIYANTO , MOCHAMMAD SODIQ , NOENG M. NURCAHYANI.2010. Keanekaragaman Serangga Hama dan Musuh Alami pada Lahan Pertanaman Kedelai di Kecamatan Balong-Ponorogo. Jurnal Entomologi Indonesia.Vol 7, No 2

[139] Wahyudi, Henricus Ganjar, -, Sarto, -, Hadiman.2010. STUDI PEMANFAATAN BUNGKIL JARAK PAGAR (JATROPHA CURCAS L.) SEBAGAI BAHAN BAKU PESTISIDA ALAMI; STUDY ON CAKE FROM JATROPHA CURCAS LINN USED AS NATURAL PESTICIDE MAIN SUBSTANCE. Jurnal Sistem Teknik.Vol 1

[140] Santi, Sri Rahayu, Sukadana, I M,, Bogoriani, W.2011. PELATIHAN

MEMBUAT SABUN MANDI ANTI BAKTERI ALAMI DARI DAUN MIMBA (Azadirachta indica A.Juss) DI DESA PENARUKAN KERAMBITAN TABANAN. Jurnal Udayana Mengabdi.Vol 10, No 2

[141] Ibrahim, Bustami, Suptijah, Pipih, Zahid, Ahmad.2012.

EFEKTIVITAS KITOSAN MIKROKRISTALIN SEBAGAI ALTERNATIF ANTIBAKTERI ALAMI DALAM 
MOUTHWASH. Jurnal Pengolahan Hasil Perikanan Indonesia.Vol 15, No 2

[142] Salim, Emil, Van Rate, Johanes. 2012.STUDI SISTEM PENCAHAYAAN DAN PENGHAWAAN ALAMI PADA TIPOLOGI UNDERGROUND BUILDING.Jurnal Arsitektur DASENG.Vol 1.

[143] Bogoriani, Ni Wayan.2011.STUDI PEMANFAATAN CAMPURAN ZAT WARNA ALAMI DAN ASAM SITRAT SEBAGAI MORDAN TERHADAP KAYU JENIS AKASIA DENGAN METODE SIMULTAN MORDANTING. Journal of Chemistry.Vol. 5, No. 1

[144] Sukardi ..2011. IDENTIFIKASI DAN KARAKTERISASI UMBI KELADI TIKUS SEBAGAI ZAT ANTIOKSIDAN ALAMI. . Jurnal Gamma.Vol 6, No 2

[145] Siregar, Yusraini Dian Inayati , Nurlela, Nurlela.2011. Ekstraksi dan Uji Stabilitas Zat Warna Alami dari Bunga Kembang Sepatu (Hibiscus rosa-sinensis L) dan Bunga Rosela (Hibiscus sabdariffa L). VALENSI.Vol 2, No 3

[146] Risa Nofiani, Melani Setyiasi Puji Ardiningsih.2013. ANALISIS ORGANOLEPTIK PRODUK BUBUK PENYEDAP RASA ALAMI DARI EKSTRAK DAUN SANSAKNG (Pycnarrhena cauliflora Diels). Jurnal Kimia Khatulistiwa.Vol 2, No 1

[147] Saam, Zulfan, Yakub, Elni.2012. Analisis Masalah -Masalah Belajar Yang Di Alami Oleh Siswa Kelas Akselerasi Dan Unggulan Di SMP Negeri Kota Dumai. Jurnal Pendidikan.Vol 3, No 02

[148] Ibrahim, Bustami, Suptijah, Pipih, Zahid, Ahmad.2012. EFEKTIVITAS KITOSAN MIKROKRISTALIN SEBAGAI ALTERNATIF ANTIBAKTERI ALAMI DALAM MOUTHWASH. Jurnal Pengolahan Hasil Perikanan Indonesia.Vol 15, No 2

[149] Ridwan Rais, Ichwan. 2015. ISOLASI DAN PENENTUAN KADAR FLAVONOID EKSTRAK ETANOLIK HERBA SAMBILOTO (Andrographis paniculata (BURM.F.) NESS). PHARMACIANA. Vol 5, No 1 . 
[150] Sukadana, I M.. 2009. SENYAWA ANTIBAKTERI GOLONGAN FLAVONOID DARI BUAH BELIMBING MANIS (Averrhoa carambola Linn.L). Journal of Chemistry. Vol. 3, No. 2 

